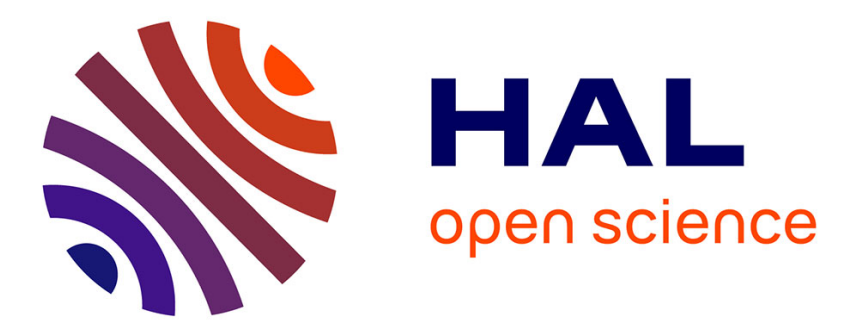

\title{
Rhodium-catalyzed aqueous biphasic hydrogenation of alkenes with amphiphilic phosphine-containing core-shell polymers
}

Ahmad Joumaa, Si Chen, Sandrine Vincendeau, Florence Gayet, Rinaldo Poli, E. Manoury

\section{To cite this version:}

Ahmad Joumaa, Si Chen, Sandrine Vincendeau, Florence Gayet, Rinaldo Poli, et al.. Rhodiumcatalyzed aqueous biphasic hydrogenation of alkenes with amphiphilic phosphine-containing core-shell polymers. Molecular Catalysis, 2017, 438, pp.267-271. 10.1016/j.mcat.2017.06.005 . hal-01940163

\section{HAL Id: hal-01940163 https://hal.science/hal-01940163}

Submitted on 1 Mar 2021

HAL is a multi-disciplinary open access archive for the deposit and dissemination of scientific research documents, whether they are published or not. The documents may come from teaching and research institutions in France or abroad, or from public or private research centers.
L'archive ouverte pluridisciplinaire HAL, est destinée au dépôt et à la diffusion de documents scientifiques de niveau recherche, publiés ou non, émanant des établissements d'enseignement et de recherche français ou étrangers, des laboratoires publics ou privés. 


\title{
Rhodium-catalyzed aqueous biphasic hydrogenation of alkenes with amphiphilic phosphine-containing core-shell polymers.
}

\author{
Ahmad Joumaa, ${ }^{a}$ Si Chen, ${ }^{a}$ Sandrine Vincendeau, ${ }^{a}$ Florence Gayet, ${ }^{a}$ Rinaldo Poli, ${ }^{* a, b}$ and \\ Eric Manoury*a
}

${ }^{a}$ CNRS, LCC (Laboratoire de Chimie de Coordination), Université de Toulouse, UPS, INPT, 205 route de Narbonne, BP 44099, F-31077 Toulouse Cedex 4, France CNRS. Fax: +33561553003; Tel: +33-561333174; E-mails: rinaldo.poli@lcc-toulouse.fr, eric.manoury@lcctoulouse.fr.

${ }^{b}$ Institut Universitaire de France, 1, rue Descartes, 75231 Paris Cedex 05, France.

\begin{abstract}
The biphasic aqueous hydrogenation reaction of styrene and 1-octene could be efficiently carried out using phosphine-containing core-shell water-soluble polymers used as nanoreactors in presence of $[\mathrm{Rh}(\mathrm{COD}) \mathrm{Cl}]_{2}$. The catalytic aqueous phase could be successfully recycled up to six times.
\end{abstract}

Keywords: Aqueous biphasic catalysis; Alkene hydrogenation; Water-confined nanoreactors; Rhodium; Recycling. 


\section{Introduction}

Hydrogenation is clearly a major reaction in organic synthesis both at the laboratory and industrial scale. It has been reported that at least one catalytic hydrogenation step is included in around $25 \%$ of all chemical processes. ${ }^{1}$ Hydrogenation is applied at the very large scale such as, for instance, for the desulfurization of fuels, ${ }^{2,3}$ but is also largely used for the production of fine chemicals, ${ }^{4}$ including chiral ones. ${ }^{5,6,7,8}$ As a way to improve the efficiency of chemical processes $^{9}$ in economic and environmental terms, biphasic aqueous catalysis is an elegant approach because it simplifies the catalyst separation by simple decantation and its subsequent recycling. This operational mode has found large scale industrial implementation in hydroformylation, ${ }^{10,11,12}$ but has also been used for hydrogenation reactions. ${ }^{13}$ Within this approach, the catalyst is usually confined in the aqueous phase ${ }^{14}$ while substrates and products are in the water-immiscible organic phase. The (pre)catalysts may be water-soluble complexes $^{15,16,17,18,19,20,21,22,23}$ or metal nanoparticles dispersed in water. ${ }^{24,25,26,27,28,29,30,31,32,33}$

We have recently reported a new approach in aqueous biphasic catalysis, which consists of using stable latexes of unimolecular polymeric nanoreactors, characterized by a well-controlled core-shell structure with a narrow size distribution around $100 \mathrm{~nm}$ and a spherical morphology 34,35 They were synthesized by controlled RAFT polymerization in water, yielding stable dispersions with a $25-30 \%$ polymer content in weight in a one-pot procedure. The polymeric nano-objects remain confined in the aqueous phase by virtue of their hydrophilic shell but contain a phosphine-functionalized core where the (pre)catalyst is covalently bound. The hydrophobic cores are swollen very rapidly by various organic compounds. ${ }^{36}$ We have shown that the $\left[\mathrm{Rh}(\mathrm{acac})(\mathrm{CO})_{2}\right]$ precatalyst can be coordinated inside the polymer core $\mathrm{e}^{36,37,38}$ and the resulting metal-loaded nanoreactors were successfully used in the aqueous biphasic hydroformylation of 1-octene with excellent activity, low metal leaching, facile catalyst recovery and efficient recycling. ${ }^{36,39,40,41}$ We have also shown that other metal complexes, notably $[\mathrm{RhCl}(\mathrm{COD})]_{2}$, can be incorporated inside the polymer core, but the resulting objects were only studied in terms of coordination chemistry and interparticle metal migration dynamics and mechanism. ${ }^{37,38}$ In the present contribution, we report the first application of these amphiphilic core-shell polymers to the biphasic aqueous hydrogenation of alkenes. 


\section{Experimental}

\subsection{General Considerations.}

Chloro(1,5-cyclooctadiene)rhodium(I) dimer, (98\%, Strem), 1-octene (99+\%, Acros), 1-nonanol (> 99\%, Alfa TCI), $n$-decane (99\%, Aldrich), $n$-dodecane (99\%, Acros), toluene (99\%, Acros) and anisole (99.0\%, Fluka) were used as received. Styrene (99\%, Acros) was purified by passing it through a column of active basic aluminum oxide to remove the stabilizer. Dihydrogen was obtained from Linde Gas. The triphenylphosphine (TPP) containing core cross-linked micelles, TPP@CCM1 ${ }^{34}$ and TPP@CCM2 $2^{40}$, were synthesized as described in our previous contributions and stored under an inert atmosphere.

\subsection{Catalytic tests.}

2.2.1 General procedure for the hydrogenation of styrene or 1-octene under biphasic conditions.

In a Schlenk tube under argon was added 1mL of latex (for TTP@CCM1: $0.12 \mathrm{mmol}$ of TPP; (for TTP@CCM2: $0.063 \mathrm{mmol}$ of TPP) and $2 \mathrm{~mL}$ of $\mathrm{H}_{2} \mathrm{O}$. Toluene $(0.2 \mathrm{~mL})$ was then added to swell the particles and the reaction mixture was stirred for $1 \mathrm{~min}$. Then, a solution of [Rh(COD)Cl $]_{2}$ (for TPP@CCM1: $15.4 \mathrm{mg}(0.03 \mathrm{mmol}$; P:Rh = 2); for TPP@CCM2: $3.77 \mathrm{mg}$ $(0.0078 \mathrm{mmol} ; \mathrm{P}: \mathrm{Rh}=4)$ in toluene $(0.3 \mathrm{~mL})$ was added and the reaction mixture was stirred for $10 \mathrm{~min}$ at RT. The aqueous phase became yellow while the toluene phase became colorless. Separately, a stock organic phase was prepared with the substrate (for styrene: $3.17 \mathrm{~g}, 30 \mathrm{mmol}$; for 1-octene: $3.37 \mathrm{~g}, 30 \mathrm{mmol})$ and decane $(1.26 \mathrm{~g}, 9 \mathrm{mmol})$ as internal standard in $40 \mathrm{~mL}$ of the desired solvent to obtain a substrate concentration of $0.75 \mathrm{mmol} / \mathrm{ml}$. For the reaction without solvent, a mixture containing $0.823 \mathrm{~g}$ of styrene $(7.9 \mathrm{mmol})$ and $0.766 \mathrm{~g}$ of decane $(5.38 \mathrm{mmol})$ was prepared.

In a vial containing a magnetic stirrer under argon was added $0.5 \mathrm{~mL}$ of the aqueous phase containing the core cross-linked micelles and the rhodium precursor (see above) and 1 $\mathrm{mL}$ of the organic stock solution (see above). The vial was placed in a steel reactor, which was then charged with 20 bar of dihydrogen. The reaction mixture was then stirred at RT for $18 \mathrm{~h}$ with magnetic stirring set at a speed of $1200 \mathrm{rpm}$. After stopping the stirring and an additional $4 \mathrm{~h}$ decantation under dihydrogen pressure, the reactor was vented and then flushed with argon. The organic layer was then withdrawn by syringe and the aqueous phase was extracted by two portions of $0.5 \mathrm{~mL}$ of diethylether, all these operations being conducted under argon. The combined organic solutions were then analyzed by GC. 
For the recycling experiments, a new portion of the substrate stock solution was added to the vial under argon and the reaction was carried out as described above.

\subsubsection{Kinetic studies.}

The investigations under biphasic conditions were carried out as described in the previous section, using several identical vials. The reaction in each vial was stopped at a different reaction time before the GC analysis.

For the homogenous catalytic reactions, triphenylphosphine $(39.3 \mathrm{mg}, 0.15 \mathrm{mmol})$, styrene $(1.56 \mathrm{~g}, 15 \mathrm{mmol})[\mathrm{Rh}(\mathrm{COD}) \mathrm{Cl}]_{2}(18.5 \mathrm{mg}, 0.0375 \mathrm{mmol})$, and dodecane as GC standard (0.66 mg, $3.75 \mathrm{mmol})$ were dissolved in deoxygenized anisole (17.6 g) and used as stock solution. Several different vials with $2 \mathrm{ml}$ each of the stock solution were used as described above.

\subsubsection{High resolution ICP-MS.}

The rhodium catalyst leaching to the organic phase was measured using high resolution ICP-MS on a XR Thermo Scientific Element. For the sample preparation, the recovered organic phase was diluted into water using a $10^{5}$ volumetric dilution factor. In practice, a $1 \mathrm{~L}$ volumetric flask was filled at $\sim 2 / 3$ with milli-Q water, then $10 \mu \mathrm{L}$ of the organic product phase were introduced using a Gilson P20 precision pipette. Borders were rinsed and the flask was introduced into an ultrasound bath for 1 hour. The solution was left overnight and the dilution was then completed with milli-Q water to the $1 \mathrm{~L}$ mark. Standards were prepared using solutions of $\mathrm{Rh}(\mathrm{acac})(\mathrm{CO}) \mathrm{TPP}$ in nonanol at various weight fractions of $\mathrm{Rh}$ in the $(0.001-0.5) \cdot 10^{-9}$ range (1-500 ppt).

\section{Results and discussion}

\subsection{Preliminary catalytic tests}

Two different polymer samples, TPP@CCM1 and TPP@CCM2, prepared as described in a previous report, ${ }^{36,37}$ have been used in this study. They contain unimolecular nanoreactors in which the spherical polymer particles are characterized by three distinct zones (see Fig. 1): a hydrophilic shell with an average of 30 monomers (50:50 mixture of methacrylic acid, MAA, and poly(ethylene oxide) methyl ether methacrylate, PEOMA) per chain, linear hydrophobic chains in the intermediate zone with an average of 300 monomer units per chain consisting of a mixture of styrene and diphenylphosphinostyrene (DPPS), and an inner cross-linked core with 
additional styrene and the cross-linking monomer, diethylene glycol dimethacrylate (DEGDMA) in a 90:10 ratio for a total of 100 monomers per chain. The two samples differ in the DPPS content in the intermediate hydrophobic layer: $10 \%$ for CCM1 and 5\% for CCM2.

The TPP@CCM1 sample was first used in the hydrogenation of styrene with toluene as organic solvent, after charging the polymer particles with the $[\mathrm{Rh}(\mathrm{COD}) \mathrm{Cl}]_{2}$ precatalyst as described in the Experimental part. ${ }^{38}$ This first test was carried out under the conditions depicted in Scheme 1 with a substrate/P/Rh ratio of 200/2/1. After $18 \mathrm{~h}$ at $\mathrm{RT}$ under $\mathrm{H}_{2}$ pressure, although the transformation of styrene to ethylbenzene was complete, the decantation process proved very problematic: only a small portion of the organic phase was observed at the top of the reaction vial, while the aqueous phase and most of the organic materials had formed a stable dense phase with the aspect of a gel. The failure of the mixture to properly decant obviously precludes an efficient product recovery and the recycling of the aqueous catalytic phase.
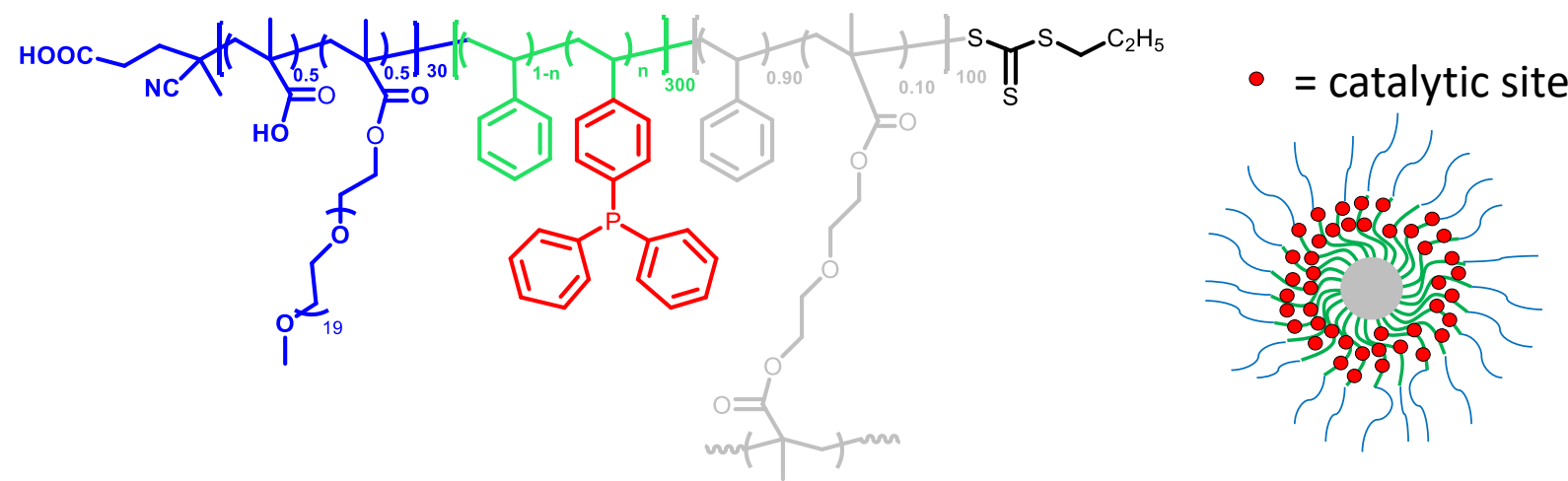

Figure 1. Structure of the reference core cross-linked micelles (TPP@CCM1 ( $=0.10)$ and TPP@CCM2 $(\mathrm{n}=0.05))$ from Zhang et al. ${ }^{36}$ and Chen et al. ${ }^{37}$
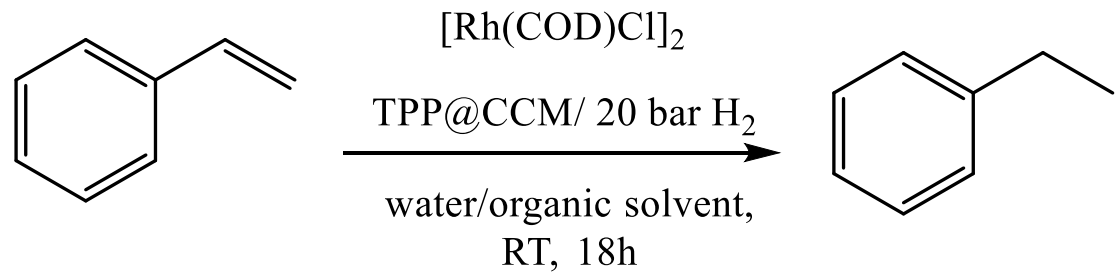

Scheme 1. Hydrogenation of styrene under biphasic conditions. Solvent = toluene or 1-nonanol. Styrene/P/Rh=200/2/1.

\subsection{Hydrogenation reactions of styrene in 1-nonanol}

We imagined that the behavior observed in the above preliminary test may result from interparticle coupling with formation of a macrogel. This hypothesis comes from our previous 
finding of rapid and reversible (in the absence of chemical reaction) interpenetration of the particles, involving core-core contact. ${ }^{37}$ This was proven by the irreversible particle aggregation in the presence of reactions leading to products in which the metal centers binds more than one TPP ligand. In the present case, after precatalyst activation involving COD removal as hydrogenated products, the unsaturated metal center with be stabilized by TPP, $\mathrm{H}_{2}$ and substrate coordination, with TPP being the preferred ligand. Since the P/Rh ratio is 2 , species such as $\left[\mathrm{RhCl}(\mathrm{TPP})_{2}\right]_{2},\left[\mathrm{RhH}_{2} \mathrm{Cl}(\mathrm{TPP})_{2}\right]_{2}$, or mononuclear olefin adducts should form. In any case, however, the presence of easily available coordination sites and the occurrence of interparticle core-core contact is likely to lead to particle coupling because of Rh binding to TPP ligands that belong to different particle cores resulting in macrogelation. On the basis of this hypothesis, we considered that a slightly coordinating solvent, even though less strongly binding than TPP, could help avoid the nanoparticle coupling by virtue of its large concentration (mass effect) but without completely blocking the catalytic sites. Indeed, using 1-nonanol as solvent, the hydrogenation took place at reasonable speed and a perfect phase separation was witnessed at the end of the reaction. The conversion of styrene was complete under the conditions indicated in Scheme 1, with ethylbenzene as the only product. The aqueous phase could be even recycled once without loss of activity. The reason for choosing a long linear chain alcohol is to maintain a biphasic system, since 1-nonanol has negligible water solubility. Monophasic reaction mixtures would be obtained by using smaller alcohols like methanol or ethanol.

The kinetics of the styrene hydrogenation under these conditions was studied and compared with the homogenous version in anisole with free triphenylphosphine as supporting ligand and carried out with identical temperature, dihydrogen pressure, and substrate/ $\mathrm{P} / \mathrm{Rh}$ ratio (see figure 2). Under the biphasic conditions, $18 \mathrm{~h}$ are needed to reach full conversion, which is a rather interesting performance even though the rate is clearly slower than for the corresponding homogenous version, where full conversion is achieved in $10 \mathrm{~h}$. The monophasic version exhibits a classical kinetic profile, with an induction time related to the precatalyst activation phase, which requires cyclooctadiene hydrogenation. ${ }^{42,43}$ This induction phase is partially visible also in the biphasic reaction. The subsequent conversion rate after the catalyst activation phase is probably limited by mass transport in and out of the nanoreactor cores. 


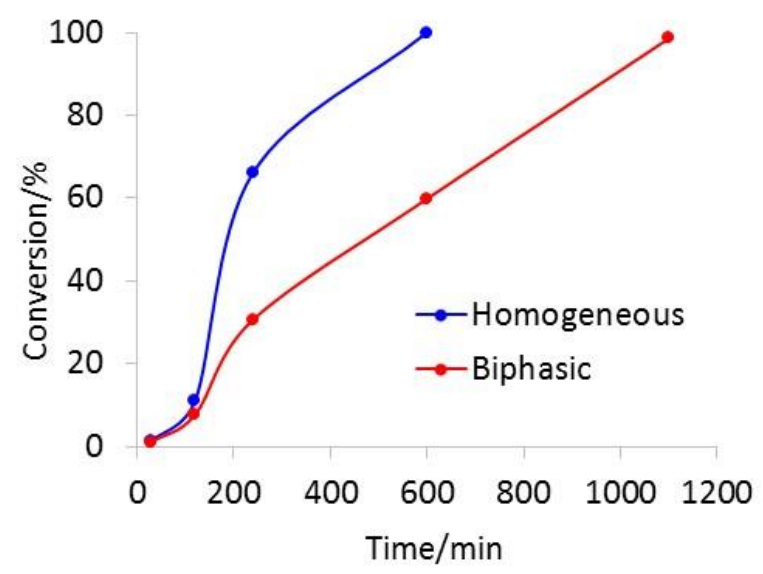

Figure 2. Styrene conversion during the Rh-catalyzed hydrogenation under homogeneous (free triphenylphosphine in anisole) and biphasic (TPP@CCM1 and 1-nonanol as substrate solvent) conditions. $\mathrm{P}\left(\mathrm{H}_{2}\right)=20$ bar; styrene/P/Rh = 200/2/1; room temperature.

\subsection{Hydrogenation reactions of 1-octene in 1-nonanol}

The same conditions that allowed us to achieve the biphasic hydrogenation of styrene were next extended to 1-octene (scheme 2 ). This substrate could be efficiently hydrogenated with the Rh catalyst supported in the TPP@CCM1 nanoreactors and the catalytic aqueous phase could be recycled up to 6 times (see table 1). After 6 recycles, the catalytic activity remained high (full conversion), but the octane selectivity decreased to $90 \%$, suggesting that the catalytically active species may have experience some modification. The rhodium leaching was relatively low, around $0.5 \mathrm{ppm}$. Note that this leaching level is significantly lower than that observed with the same nanoparticles in the hydroformylation of 1-octene. ${ }^{36,40}$ This is probably a consequence of the milder reaction temperature. Indeed, we have shown that the Rh leaching in the hydroformylation reaction, which is conducted at $90^{\circ} \mathrm{C}$, is directly correlated with the Upper Critical Solution Temperature (UCST) behavior of the POEMA monomers in the hydrophilic shell, which induce a slight compatibilization of the polymer shell with the organic phase at high temperature. ${ }^{40}$

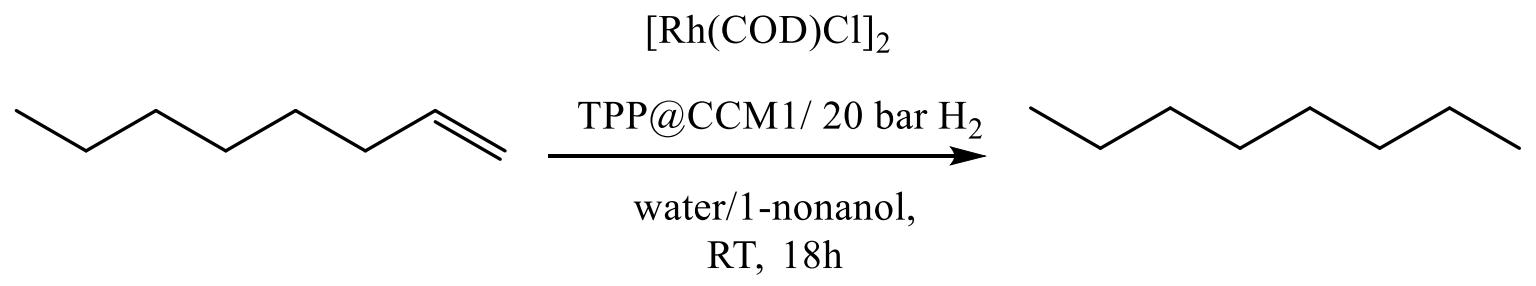

Scheme 2. Hydrogenation of 1 -octene under biphasic conditions. Styrene/P/Rh=200/2/1. 
Table 1. Results of recycle runs for the 1-octene hydrogenation under biphasic conditions with TPP@CCM1. ${ }^{\mathrm{a}}$

\begin{tabular}{|c|c|c|c|c|}
\hline $\begin{array}{l}\text { Recycle } \\
\text { number }\end{array}$ & $\begin{array}{c}\text { 1-octene } \\
\text { conversion/\% }\end{array}$ & $\begin{array}{l}\text { Octane } \\
\text { yield } / \%\end{array}$ & $\begin{array}{c}\text { 2-octenes }^{b} \\
\text { Yield/\% }\end{array}$ & {$[\mathrm{Rh}]_{\text {org }} / \mathbf{p p m}$} \\
\hline- & 100 & 99 & 0 & 0.55 \\
\hline 1 & 100 & 96 & 0 & 0.63 \\
\hline 2 & 100 & 98 & 0 & 0.45 \\
\hline 3 & 100 & 93 & 2 & 0.45 \\
\hline 4 & 100 & 92 & 6 & 0.46 \\
\hline 5 & 100 & 91 & 6 & 0.30 \\
\hline 6 & 100 & 90 & 9 & 0.59 \\
\hline
\end{tabular}

${ }^{a}$ Reaction conditions as shown in Scheme 2. ${ }^{\mathrm{b}}$ As a mixture of cis and trans isomers.

\subsection{Hydrogenation reactions of styrene under other conditions}

We have imagined that the macrogelation phenomenon observed in the preliminary catalytic test described in section 3.1 could also be limited or suppressed by increasing the $\mathrm{P} / \mathrm{Rh}$ ratio and by using a less-densely functionalized by triphenylphosphine (TPP) core cross-linked micelles, namely TPP@CCM2 (see figure 1). This way, each Rh atom would be able to find nearby, within the same nanoreactor core, a sufficient number of ligands to stabilize itself.

Using TPP@CCM2 and a P/Rh ratio of 4, the catalytic reaction was carried out with three different organic solvents, as well as without solvent (see table 2). Under all these conditions (table 2, entries 1, 3, 4 and 7), the conversions were high and a clear phase separation was observed. It is worth pointing out that, for the hydrogenation without solvent, the conversion remains high in spite of the greatly increased substrate/Rh ratio (4000), with a quantitative conversion for the first two runs (entries 7 and 8). However, the ethylbenzene selectivity was relatively low under these conditions, as well as in 1-nonanol. A limited number of recycling experiments were also carried out under these conditions. Recycling was especially efficient in terms of catalytic activities and ethylbenzene selectivities for the catalysis with toluene as solvent up to the third run (table 2, entries 4, 5 and 6). Both in 1-nonanol and under solvent-free conditions, the reaction rates were even slightly higher in the second run than in the first run (table 2, entries $1 / 2$ and $7 / 2$ ), probably because of an induction in precatalyst activation $^{42,43}$ during the first runs. 

Table 2. Hydrogenation of styrene under biphasic conditions with TPP@CCM2 and a P/Rh ratio of $4 .^{\mathrm{a}}$

\begin{tabular}{|c|c|c|c|}
\hline Entry & solvent & Styrene conversion & $\begin{array}{c}\text { Yield of } \\
\text { ethylbenzene }\end{array}$ \\
\hline 1 & 1 -nonanol (first run) & $95.2 \%$ & $85.3 \%$ \\
\hline 2 & 1 -nonanol (second run) & $100 \%$ & $83.6 \%$ \\
\hline 3 & 1 -nonanol/toluene & $99.6 \%$ & $98.3 \%$ \\
\hline 4 & $(1 / 1$, v/v) & & $99.8 \%$ \\
\hline 5 & toluene (first run) & $100 \%$ & $98.9 \%$ \\
\hline 6 & toluene (second run) & $100 \%$ & $99.5 \%$ \\
\hline 7 & no solvent (first run) & $99.4 \%$ & $92.4 \%$ \\
\hline 8 & no solvent (second run) & $100 \%$ & $84.2 \%$ \\
\hline 9 & no solvent (third run) & $79.4 \%$ & $79.0 \%$ \\
\hline
\end{tabular}

${ }^{\text {a }}$ Conditions as in Scheme 1, except styrene/P/Rh $=400 / 4 / 1$ for entries 1-6 and 4000/4/1 for entries 7-9.

\section{Conclusions}

We have shown that the triphenylphosphine-functionalized core-shell polymers TPP@CCM1 and TPP@CCM2 can be successfully used in the biphasic aqueous hydrogenation of simple alkenes (styrene and 1-octene). We have shown that we can avoid the polymer macrogelation during the reaction by either using 1-nonanol as solvent or by increasing the $\mathrm{P} / \mathrm{Rh}$ ratio to 4 . The catalytic aqueous phase can be recycled efficiently at least 6 times, but the activities and the selectivities are slightly eroded in some cases. We are now investigating ways to further stabilize the catalytic species and to optimize the nanoreactor structure in order to improve the catalytic efficiency and recyclability.

\section{Acknowledgment}

We are grateful to the "Agence Nationale de la Recherche" (ANR) for support of this work through grant "BIPHASNANOCAT" (ANR-11-BS07--025--01). AJ thanks the City Council of Houmine El Fawka (Lebanon) for a Ph.D. fellowship. Additional support from the 
"Centre National de la Recherche Scientifique" (CNRS) and from the "Institut Universitaire de France" (IUF) is also gratefully acknowledged.

\section{References}

[1] G. Vilé, D. Albani, N. Almora-Barrios, N. Lopez, J. Perez-Ramirez, ChemCatChem, 8 (2016) 21.

$\left.{ }^{2}\right]$ E. Pedernera, R. Reimert, N. L. Nguyen, V. Van Buren, Catal. Today, 79-80 (2003), 371.

[3] J. P. van den Berg, J. P. Lucien, G. Germaine, G. L. B. Thielemans, Fuel Processing Technol., 35 (1993), 119.

$\left[{ }^{4}\right]$ H.-U. Blaser, C. Malan, B. Pugin, F. Spindler, H. Steiner, M. Studer, Adv. Synth. Catal., 345 (2003), 103.

[5] N. B. Johnson, I. C. Lennon, P. H. Moran, J. A. Ramsden, Acc. Chem. Res., 40 (2007), 1291.

[6] D. J. Ager, A. H. M. de Vries, J. G. de Vries, Chem. Soc. Rev., 41 (2012), 3340.

[7] X. Cui, K. Burgess, Chem. Rev., 105 (2005), 3272.

[8] P. Etayo, A. Vidal-Ferran, Chem. Soc. Rev., 42 (2013), 728.

[9] R. A. Sheldon, Chem. Soc. Rev., 41 (2012), 1437.

[10] B. Cornils, W. A. Herrmann, I. T. Horvath, W. Leitner, S. Mecking, H. Olivier-Bourbigou, D. Vogt Eds., Multiphase Homogeneous Catalysis (Wiley-VCH: Weinheim, Germany, 2005)

[11] B. Cornils, W. A. Herrmann Eds., Aqueous-Phase Organometallic Catalysis (Wiley-VCH: Weinheim, Germany, 2005)

[12] B. Cornils, J. Mol. Cat. A: Chem., 143 (1999), 1.

[13] F. Joo, Acc. Chem. Res., 35 (2002), 738.

[14] For a catalytic system where substrates and products are water-soluble when catalysts are confined in organic phase, see: C. G. Piscopo, F. Gallou, W. Leitner, G. Francio, Synthesis, 49 (2017), 353.

[15] S. Paganelli, M. Mahbubul, Alam, V. Beghetto, A. Scrivanti, E. Amadio, M. Bertoldini, U. Matteoli, Appl. Catal.A. : Gen., 503 (2015), 20.

[16] A. O. Ogweno, S. O. Ojwach, M. P. Akerman, Appl. Catal. A.: Gen., 486 (2014), 250.

[17] K. Voronova, M. Purgel, A. Udvardy, A. C. Benyei, A. Katho, F. Joo, Organometallics, 32 (2013), 4391.

[18] C. Stangel, G. Charalambidis, V. Varda, A. G. Coutsolelos, I. D. Kostas, Eur. J. Inorg. Chem., (2011), 4709.

[19] V. Kotzabasakis, N. Hadjichristidis, G. Papadogianakis, J. Mol. Cat. A: Chem., 304 (2009), 95.

[20] P. J. Baricelli, T. Ascanio, E. Lujano, L. G. Melean, M. Borusiak, F. Lopez-Linares, L. J. Bastidas, M. Rosales, J. Mol. Cat. A: Chem., 278 (2007), 107.

[21] S. Di Dio, M. Marchetti, S. Paganelli, O. Piccolo, Appl. Catal. A.: Gen., 399 (2011), 205.

[22] I. Rojas, F. Lopez Linares, N. Valencia, C. Bianchini, J. Mol. Cat. A: Chem., 144 (1999), 1.

[23] W.-C. Chan, C.-P. Lau, L. Cheng, Y.-S. Leung, J. Organomet. Chem., 464 (1994), 103. [24] M. Guerrero, N. T. T. Chau, S. Noël, A. Denicourt-Nowicki, F. Hapiot, A. Roucoux, E. Monflier, K. Philippot, Curr. Org. Chem., 17 (2013), 364.

[25] N. T. T. Chau, S. Menuel, S. Colombel-Rouen, M. Guererro, E. Monflier, K. Philippot, A. Denicourt-Nowicki, A. Roucoux, RSC Advances, 6 (2016), 108125. 
[26] B. L. Albuquerque A. Denicourt-Nowicki, C. Mériadec, J. B. Domingos, A. Roucoux, J. Catal., 340 (2016), 144.

[27] L. Gao, K. Kojima, H. Nagashima, Tetrahedron, 71 (2015), 6414.

[28] S. Bulut, Z. Fei, S. Siankevich, J. Zhang, N. Yan, Catal. Today, 247 (2015), 96.

[29] M. Caporali, A. Guerriero, A. Ienco, S. Caporali, M. Peruzzini, L. Gonsalvi, ChemCatChem, 5 (2013), 2517.

[30] N. T. T. Chau, J.-P. Guégan, S. Menuel, M. Guererro, F. Hapiot, E. Monflier, K. Philippot, A. Denicourt-Nowicki, A. Roucoux, Appl. Catal. A.: Gen., 467 (2013), 497.

[31] N. T. T. Chau, S. Handjani, J.-P. Guégan, M. Guererro, E. Monflier, K. Philippot, A. Denicourt-Nowicki, A. Roucoux, ChemCatChem, 5 (2013), 1497.

[32] M. V. Vasylyev, G. Maayan, Y. Hovav, A. Haimov, R. Neumann, Org. Lett., 8 (2006), 5445.

[33] C. Larpent, E. Bernard, F. Brisse-le Menn, H. Patin, J. Mol. Cat. A: Chem., 116 (1997), 277.

[34] R. Poli, S. Chen, X. Zhang, A. F. Cardozo, M. Lansalot, F. D’Agosto, B. Charleux, E. Manoury, F. Gayet, C. Julcour, J.-F. Blanco, L. Barthe, H. Delmas, ACS Symposium Series, 1188 (Controlled Radical Polymerization) (2015), 203.

[35] E. Manoury, F. Gayet, F. D’Agosto, M. Lansalot, H. Delmas, C. Julcour, J.-F. Blanco, L. Barthe, R. Poli, Catalysis within Nanoconfined Spaces, R. Poli, Editor; Springer: New York (2017), 147.

[36] X. Zhang, A. F. Cardozo, S. Chen, W. Zhang, C. Julcour, M. Lansalot, J.-F. Blanco, F. Gayet, H. Delmas, B. Charleux, E. Manoury, F. D’Agosto, R. Poli, Chem. Eur. J., 20 (2014), 15505.

[37] S. Chen, F. Gayet, E. Manoury, A. Joumaa, M. Lansalot, F. D’Agosto, R. Poli, Chem. Eur. J., 22 (2016), 6302.

[38] S. Chen, E. Manoury, F. Gayet, R. Poli, Polymers, 8 (2016), 26.

[39] S.Chen, A. F. Cardozo, C. Julcour, J.-F. Blanco, L. Barthe, F. Gayet, M. Lansalot, F. D’Agosto, H. Delmas, E. Manoury, R. Poli, Polymer, 72 (2015), 327.

[40] A. F. Cardozo, C. Julcour, L. Barthe, J.-F. Blanco, S. Chen, F. Gayet, E. Manoury, X. Zhang, M. Lansalot, B. Charleux, F. D’Agosto, R. Poli, H. Delmas, J. Catal., 324 (2015) , 1.

[41] E. Lobry, A. F. Cardozo, L. Barthe, J.-F. Blanco, H. Delmas, S. Chen, F. Gayet, X.

Zhang, M. Lansalot, F. D’Agosto, R. Poli, E. Manoury, C. Julcour, J. Catal., 342 (2016), 164. [42] A. Preetz, H.-J. Drexler, C. Fischer, Z. Dai, A. Börner, W. Baumann, A. Spannenberg, R. Thede, D. Heller, Chem. Eur. J., 14 (2008) 1445.

[43] A. Meißner, E. Alberico, H.-J. Drexler, W. Baumann, D. Heller, Catal. Sci. Technol., 4 (2014) 3409. 